Document downloaded from:

http://hdl.handle.net/10251/154799

This paper must be cited as:

Asensi Dasí, EJ.; Alemany Martínez, E.; Duque-Sarango, P.; Aguado García, D. (2019). Assessment and modelling of the effect of precipitated ferric chloride addition on the activated sludge settling properties. Chemical Engineering Research and Design. 150:14-25. https://doi.org/10.1016/j.cherd.2019.07.018

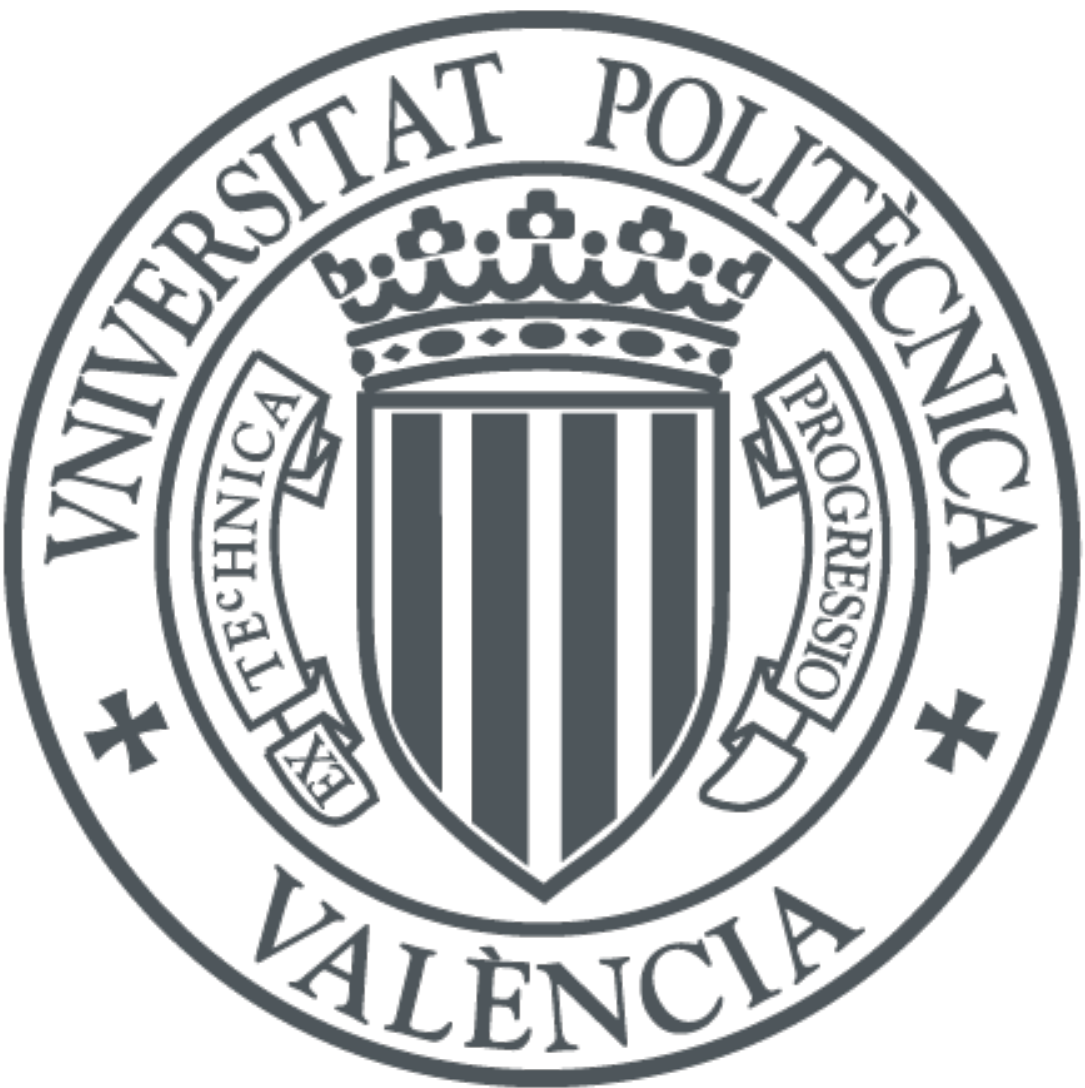

The final publication is available at

https://doi.org/10.1016/j.cherd.2019.07.018

Copyright Elsevier

Additional Information 


\title{
Assessment and modelling of the effect of precipitated ferric chloride addition on the activated sludge settling properties
}

\author{
E. Asensi ${ }^{\text {a* }}$, E. Alemany ${ }^{\mathrm{b}}$, P. Duque-Sarango ${ }^{\mathrm{c}}$, D. Aguado ${ }^{\mathrm{a}}$ \\ ${ }^{a}$ CALAGUA - Unidad Mixta UV-UPV, Institut Universitari d'Investigació d'Enginyeria de l'Aigua i Medi Ambient - \\ IIAMA, Universitat Politècnica de València, Camí de Vera s/n, 46022 Valencia, Spain. \\ ${ }^{b}$ Departamento de Matemática Aplicada. Universitat Politècnica de València. Camino de Vera s/n, 46022. Valencia. \\ Spain. \\ ${ }^{\mathrm{c} E n v i r o n m e n t a l ~ B i o t e c h n o l o g y ~ R e s e a r c h ~ G r o u p ~(I N B I A M), ~ S a l e s i a n ~ P o l y t e c h n i c ~ U n i v e r s i t y, ~ C a m p u s ~ e l ~ V e c i n o, ~ C a l l e ~}$ \\ Vieja 12-30 y Elia Liut, Cuenca, Ecuador. \\ ${ }^{*}$ Corresponding autor. E-mail: daaggar@hma.upv.es (D. Aguado)
}

\begin{abstract}
This research studies the effect of the widely used coagulant ferric chloride on the activated sludge sedimentability through a vast array of hindered settling tests considering different application modes and a wide range of reagent doses. Direct application of ferric chloride improved the hindered settling velocity (up to twice the settling velocity of the activated sludge with no coagulant addition), but sharply decreased the $\mathrm{pH}$ to levels where the biological process was unfeasible $(\mathrm{pH}<4)$. When the $\mathrm{pH}$ was adjusted during coagulation to avoid biological inhibition, the impact on the settling velocity depended on the adjusted $\mathrm{pH}$ value. When the added coagulant was previously precipitated and neutralized, no $\mathrm{pH}$ inhibition occurred and the hindered settling velocity increased linearly with the dose (up to 8 times). This velocity improvement was caused by the increase in flocs density due to the capture within the flocs of the formed precipitates. Based on these experimental results, the usefulness and reliability of the standard hindered settling velocity mathematical models used for the secondary settler design and optimization (Richardson \& Zaki model and the Vesilind's exponential model), was expanded to situations in which precipitated ferric chloride is used in wastewater treatment plants. Two empirical equations were proposed and fitted to relate these mathematical models' parameters with the dose of coagulant.
\end{abstract}

KEYWORDS: Activated sludge, Coagulant, Ferric chloride, Hindered settling velocity, Secondary settler. 


\section{INTRODUCTION}

Over several decades many wastewater treatment plants (WWTPs) have been built to protect our aquatic natural resources. Most of these WWTPs implement the activated sludge process as a biological wastewater treatment stage for organic matter and nutrient removal (Metcalf and Eddy, 2003). In this aerobic suspended growth process, the development of well-formed activated sludge flocs is of great importance (Koivuranta et al., 2014). This is due to the fact that quality of the effluent heavily depends on the efficiency of the solid-liquid separation process at the secondary settler (Christensen et al., 2015).

Therefore, considerable research attention has been devoted to improve suspended solids removal in the secondary settler. Different strategies for filamentous bacteria and foaming identification and control (Mesquita et al., 2013; Burger et al., 2017) or the addition of an inert compound (talc, bentonite, etc.), practice known as "ballasted sedimentation" (Vanderhasselt and Verstraete, 1999; Wiszniowski et al., 2007; Otal et al., 2013; Wells et al., 2015) have been explored. The suspended solids removal in a subsequent tertiary treatment process (e.g., sand filter, coagulation-flocculation, membrane filtration,...) to achieve the ever demanding WWTP effluent discharge requirements has also been studied (van Haandel and van der Lubbe, 2012). In addition, notable advances have also been made in the sludge treatment and dewatering (Li et al., 2018; Liu et al., 2018; Liu et al., 2019).

The complexity of the biological and physicochemical processes taking place in WWTPs has promoted the use of WWTP advanced mathematical modelling and simulation as a tool for the selection of appropriate operational criteria, optimization of the involved processes and for efficient design (Rivas et al., 2008). In this way, the in-depth knowledge gained along research decades has been mapped and coded into sophisticated software and mathematical algorithms. These mathematical models can reproduce most of the processes involved, like settling, volatile fatty acids elutriation, gas-liquid transfer, acid-base processes, organic matter and nutrient removal, acidogenesis, acetogenesis and methanogenesis (Barat et al., 2013).

Secondary settling tank well-established mathematical models (Li and Stenstrom, 2014) require the value of the settling velocity as a function of the suspended solids concentration. For this purpose, empirical equations are normally used in commercial tools. However, these empirical equations do not consider neither the influence of chemical precipitation nor the addition of an inert compound, on the activated sludge settling properties. This becomes especially important, as the state-of-art practice 
tends to plant-wide modelling where models of all the processes involved interact. Additionally, in most research studies with coagulant addition, the activated sludge settling characterization is based on simple measurements of sludge indexes (Li, 2005; Oikonomidis et al., 2009; De Gregorio et al., 2010; Li et al., 2012) rather than on the study of the sludge hindered settling velocity.

Ferric chloride is a chemical reagent widely used in WWTPs. It owns a high capacity to form flocs and serves well to several purposes, such as phosphate precipitation, solids removal and sludge conditioning prior to dehydration (Metcalf and Eddy, 2003; Zhang et al., 2017; Rebosura et al., 2018). There are many published studies on wastewater phosphorus removal through chemical precipitation with ferric chloride. However, the addition of this reagent affects the sedimentability of the activated sludge, and this effect has been little addressed by the scientific community. However, the effect of ferric chloride on the hindered settling velocity has not been investigated. Moreover, neither the effect of different application modes of ferric chloride nor iron doses in higher ranges than the typical ones for phosphorus precipitation have been studied.

This work addresses an interesting experimental study of the effect of ferric chloride on the activated sludge sedimentability considering different application modes and a wide range of reagent doses. For the application mode that achieved the greatest settling improvement, a mathematical model was proposed to obtain the hindered settling velocity as a function of the added reagent dose. This model can be used for the design, operation and simulation of secondary settlers of WWTPs, thus allowing to expand the usefulness and reliability of existing mathematical settling models.

\section{MATERIALS AND METHODS}

\subsection{Experimental procedure}

A total of 168 settling tests were carried out using sludge samples from Carraixet WWTP (Valencia, Spain) collected at 22 different days (sludge samples S1 - S22) covering from summer to winter seasons. Table 1 shows the activated sludge reactor characteristics.

The characteristics of the settling tests performed are given in Table 2. 34 tests were performed with sludge samples S1 - S5 to characterize the settling properties of the activated sludge from the fullscale WWTP (i.e., with no coagulant added) and 134 tests to study the influence of the ferric chloride addition on the sludge settling characteristics. Different forms of coagulant addition were tested: in 18 tests, the coagulant was added without adjusting the $\mathrm{pH}$, in 59 tests the $\mathrm{pH}$ was adjusted to a given 
desired value: $\mathrm{pH}=6,7$ and $8(\mathrm{pH}$ values compatible with the biological process) during the coagulation process, while in 20 tests, previously precipitated and neutralized ferric chloride was added. In the latter case, 37 detailed tests were performed in a more limited dose range, for mathematical modelling purposes.

Table 1. Characteristics of the activated sludge reactor from Carraixet full-scale WWTP.

\begin{tabular}{lc}
\hline \multicolumn{1}{c}{ Parameter (unit) } & Mean Value \pm standard deviation \\
\hline $\mathrm{SS}\left(\mathrm{g} \mathrm{l}^{-1}\right)$ & $3.1 \pm 0.9$ \\
$\mathrm{VSS}\left(\mathrm{g} \mathrm{l}^{-1}\right)$ & $2.6 \pm 0.7$ \\
$\mathrm{COD}\left(\mathrm{g} \mathrm{l}^{-1}\right)$ & $4.6 \pm 1.4$ \\
$\mathrm{P}_{\mathrm{T}}\left(\mathrm{mg} \mathrm{l}^{-1}\right)$ & $22.3 \pm 4.1$ \\
$\mathrm{NT}\left(\mathrm{mg} \mathrm{l}^{-1}\right)$ & $239.8 \pm 44.6$ \\
$\mathrm{pH}$ & $7.58 \pm 0.13$ \\
Alkalinity $\left(\mathrm{g} \mathrm{CaCO}_{3}{ }^{-1}\right)$ & $4.87 \pm 0.04$ \\
Conductivity $\left(\mathrm{mS} \mathrm{cm}^{-1}\right)$ & $1.83 \pm 0.18$ \\
\hline
\end{tabular}

Table 2. Sludge samples and ferric chloride dose range in the settling tests.

\begin{tabular}{|c|c|c|c|}
\hline Sludge sample & pH adjusted & $\begin{array}{c}\text { Number of } \\
\text { settling tests }\end{array}$ & $\begin{array}{l}\text { Iron dose range } \\
\quad\left(\mathrm{mg} \mathrm{Fe} \mathrm{l}^{-1}\right)\end{array}$ \\
\hline S1 - S5 & No & 34 & 0 \\
\hline $\mathrm{S} 6-\mathrm{S} 8$ & No & 18 & $0-3000$ \\
\hline $\mathrm{S} 9-\mathrm{S} 10$ & ${ }^{\mathrm{a}} \mathrm{pH}=6$ & 18 & $0-3000$ \\
\hline $\mathrm{S} 11-\mathrm{S} 14$ & ${ }^{\mathrm{a}} \mathrm{pH}=7$ & 34 & $0-3000$ \\
\hline S15 & ${ }^{\mathrm{a}} \mathrm{pH}=8$ & 7 & $0-2300$ \\
\hline \multirow[t]{2}{*}{$\mathrm{S} 16-\mathrm{S} 22$} & ${ }^{\mathrm{b}} \mathrm{pH}=7$ & 20 & $0-2000^{b}$ \\
\hline & & 37 & $0-500^{b}$ \\
\hline
\end{tabular}

a Sludge $\mathrm{pH}$ adjusted to the desired value during the coagulation process dosing $\mathrm{NaOH}$ and $\mathrm{HCl}$.

$\mathrm{b}$ The ferric chloride was neutralized and precipitated prior to its dosing (i.e., precipitated ferric chloride was added).

In WWTPs, a molar ratio between the iron dose and the initial phosphate concentration $(\mathrm{Fe} / \mathrm{P})$ greater than 1.5 is typically used to precipitate phosphates using ferric chloride (Thistleton et al., 2002; Szabó et al., 2008; Caravelli et al., 2010). Initially, a wide range of iron doses were used, between 0 and $3000 \mathrm{mg} \mathrm{Fe}^{-1}(\mathrm{Fe} / \mathrm{P}<275)$, to study the possible positive or negative effects on the activated sludge settling velocity considering different modes of ferric chloride dosing (see Table 2). Once the application mode and the optimal dose range were identified, a smaller dose range of iron between 0 and $500 \mathrm{mg} \mathrm{Fe}^{-1}(\mathrm{Fe} / \mathrm{P}<62)$ was studied. Bratby (2016) described several cases where Fe/P ratios 
of the same order of magnitude, between 2.5 and 80 , were used to obtain phosphorus concentrations lower than $0.12 \mathrm{mg} \mathrm{P}^{-1}$ in urban wastewater.

The tests were carried out on a jar-test apparatus controlled by a program and containing 1L of sludge. Ferric chloride hexa-hydrated $\mathrm{FeCl}_{3} \cdot 6 \mathrm{H}_{2} \mathrm{O}$ (molecular weight $270.30 \mathrm{~g} / \mathrm{mol}$ and 98\% purity) dissolved in deionized water was used as coagulant in tests performed with sludge samples S6 - S15. The corresponding dose of coagulant was added to the sample at the beginning of the stirring. In experiments with sludge samples $\mathrm{S} 9$ to $\mathrm{S} 15, \mathrm{NaOH}(10 \mathrm{~N})$ and $\mathrm{HCl}(1 \mathrm{~N})$ solutions were added after coagulant dosing, until the $\mathrm{pH}$ reached the desired value. In the tests with sludge samples S16 to S22, the previously precipitated and neutralized ferric chloride solution was prepared using ferric chloride hexa-hydrated dissolved in deionized water while the $\mathrm{pH}$ was monitored, and a $\mathrm{NaOH}(10 \mathrm{~N})$ solution was progressively added until the $\mathrm{pH}$ reached a value of 7 . This $\mathrm{pH}$ value was selected to avoid affecting the $\mathrm{pH}$ of the biological process when implementing the reagent dosing in the WWTP.

In the jar-test apparatus, the sample was submitted to a rapid stirring at $120 \mathrm{rpm}$ for 10 minutes, and then to a slow stirring at $25 \mathrm{rpm}$ for 20 minutes. At the end of the slow stirring, the sludge was used for settling and supernatant characterization.

The time for rapid mixing was selected so as to eliminate any possible memory effect of the sludge during the settling process (Chen et al., 1996; Asensi et al., 2019a). The initial rapid sludge stirring is used to reproduce the hydrodynamic conditions of the treatment plant where the aerators action in the biological reactor and the pumping of sludge causes the latter to experience high turbulences. Then, the sludge undergoes hydraulic flocculation at the entry of the settling tank and flow through the energy-dissipating inlet and the feed well.

\subsection{Settling tests}

Hindered settling tests were carried out as specified in van Loosdrecht et al. (2016) using 1L graduated glass cylinder. The sludge dilution was obtained using the supernatant from the secondary clarifier. The interface height in the settling tests was measured as a time dependent function. The sludge was not stirred up during the test to avoid interfering with any floc aggregation process (Chen et al., 1996). 
To evaluate the effect of the ferric chloride addition, 168 settling tests were performed as described in the experimental procedure, considering samples without coagulant addition and samples with different ferric chloride doses (Table 2). Different ways of coagulant addition were tested.

\subsection{Analytical Methods}

The concentration of soluble phosphate $\left(\mathrm{PO}_{4}{ }^{3-}-\mathrm{P}\right)$, iron $(\mathrm{Fe})$, suspended solids (SS) and volatile suspended solids (VSS) were determined according to the Standard Methods (APHA, 2012). Nonvolatile suspended solids (nVSS) were obtained as the difference between the SS and VSS. pH and temperature were measured with a portable instrument Multi 340i $\left(\mathrm{WTW}^{\circledR}\right)$.

\subsection{Mathematical and statistical Methods}

The nonlinear regressions of the mathematical models under study were fitted with the software Mathematica $\left(\right.$ Wolfram $^{\circledR}$ ). To simultaneously compare the goodness of fit of all fitted models, several criteria was considered: determination coefficient $\left(\mathrm{R}^{2}\right)$, mean square error (MSE), randomness of the distribution of errors, and standard deviation (std) and p-value of the estimated parameters of each mathematical model. Most of the graphics included in this manuscript were elaborated and laid out in Excel.

\section{RESULTS AND DISCUSSION}

\subsection{Modelling the settling characteristics of Carraixet WWTP activated sludge}

34 settling tests were carried out with the original activated sludge from the Carraixet WWTP, to characterize its settling properties and determine which mathematical model best describes the sludge hindered settling velocity. Figure 1 shows the height of the interface between the sludge and the supernatant (h) in settling tests carried out with sludge sample S3. The activated sludge hindered settling velocity (Vs) was determined by linear fit considering the zone where $h(t)$ has constant slope (resulting in all cases $\mathrm{R}^{2} \geq 0.98$ ). 


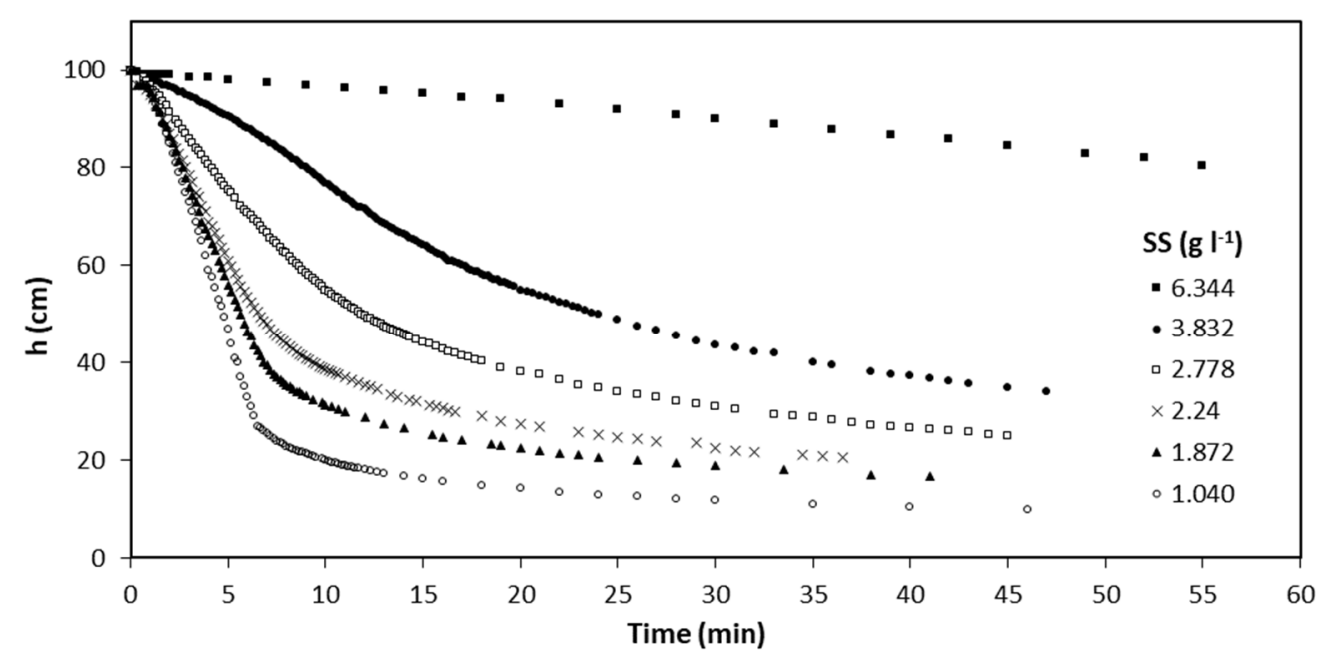

Figure 1. Time evolution of the sludge-supernatant interface for different solids concentrations in settling tests carried out with sludge sample S3.

Figure 2 shows the hindered settling velocity as a function of the suspended solids concentration for the sludge samples S1 to S5. The experimental period covered from summer to winter and, along these months, it was observed evident variability in the settling characteristics of the activated sludge from the Carraixet WWTP. The velocity as a function of the suspended solids concentration was modelled considering the mathematical models most commonly used in the bibliography to describe the hindered settling velocity (Li and Stenstrom, 2014; Asensi et al., 2019a).

Since the models were individually fitted to each sludge sample (S1 - S5), a summary table with the information obtained for each criteria from the median of the 5 sludge samples was included (see Table 3). Considering all the criteria, the best fit corresponds to Vesilind's exponential model, and the second best fit to Richardson and Zaki model. Both models yielded the highest $\mathrm{R}^{2}$ values $(>$ $0.9918)$ and the lowest MSE $\left(<0.18 \mathrm{~cm}^{2} \mathrm{~min}^{-2}\right)$, and their residues exhibit a random distribution (result which is not shown). Moreover, the values obtained for the parameters ( $k$ and $n$ ) in the mathematical fitting had small relative errors $(\operatorname{std} \mathrm{k} / \mathrm{k}<0.07$ and $\operatorname{std} \mathrm{n} / \mathrm{n}<0.09$ ) and such parameters resulted always statistically significant ( $\mathrm{p}$-value $<0.01$ ). Figure 2 shows that both models describe correctly the sludge hindered settling velocity. 


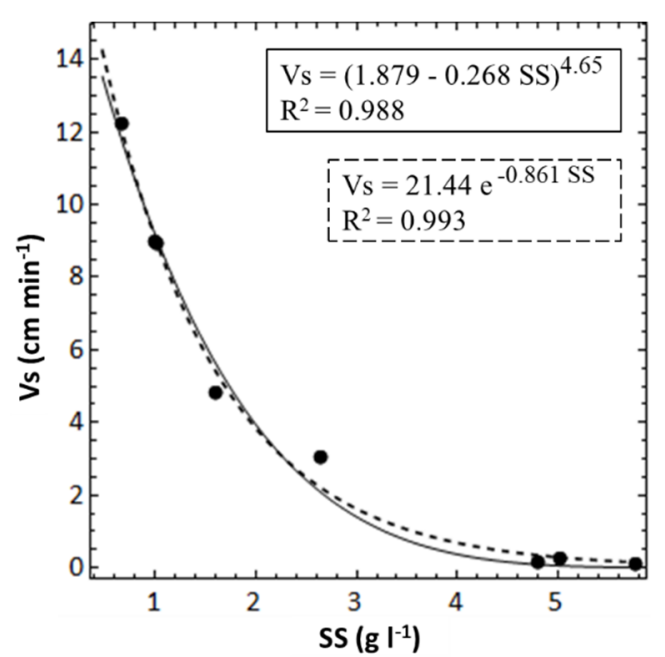

(a)

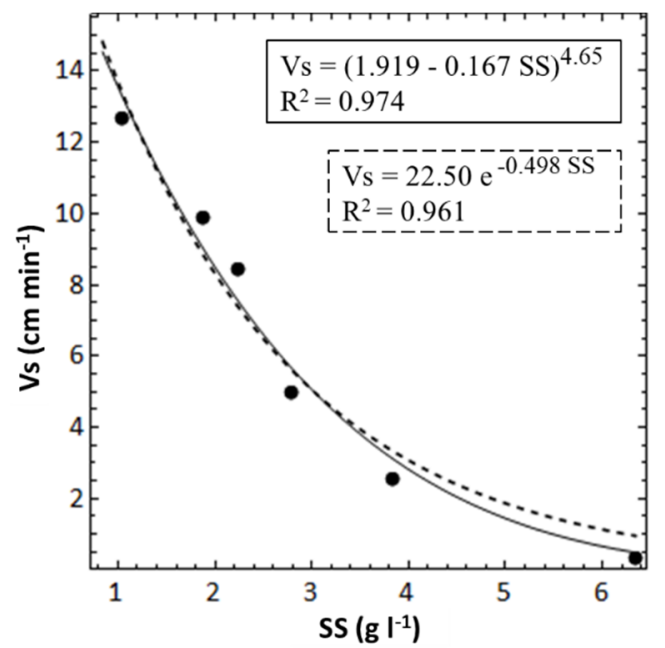

(c)

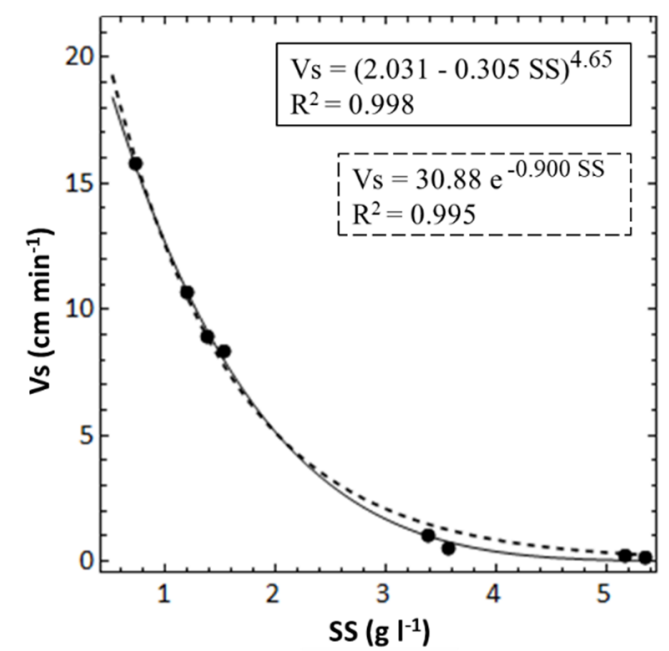

(b)

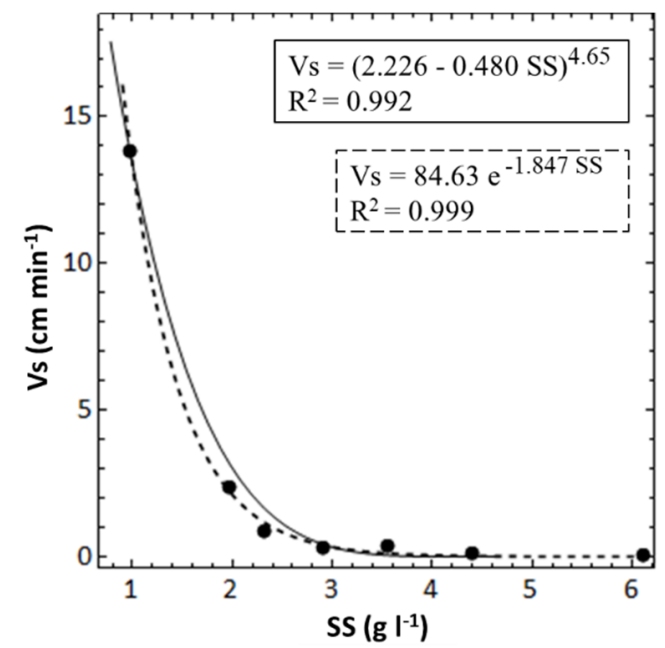

(d)

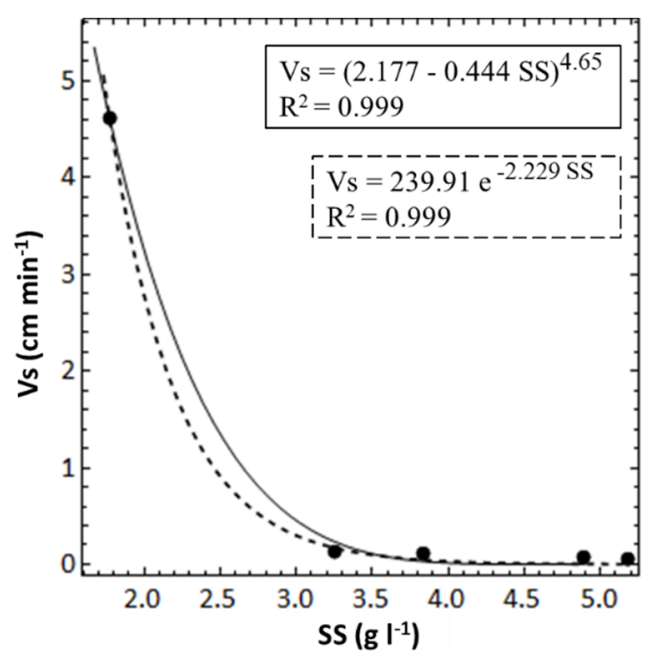

(e)

Figure 2. The two best settling velocity models fitted to data from settling test carried out with sludge samples S1 to S5. 
Table 3. Summary of the performance of different mathematical models used to describe the hindered settling velocity as a function of the suspended solids concentration. The table shows the median values for the settling tests fits carried out with the sludge samples S1 to S5.

\begin{tabular}{ccccccccc}
\hline Model & Equation & $\mathbf{R}^{\mathbf{2}}$ & $\begin{array}{c}\text { MSE } \\
\left(\mathbf{c m}^{\mathbf{2}} \mathbf{m i n}^{-2} \mathbf{)}\right.\end{array}$ & std k/k & std n / n & p-value k & p-value n \\
\hline Exponential & $\mathrm{Vs}=\mathrm{k} \cdot \mathrm{e}^{-\mathrm{nSS}}$ & 0.9947 & 0.1421 & 0.07 & 0.08 & $1.19 \mathrm{E}-03$ & $1.46 \mathrm{E}-05$ \\
Potential & $\mathrm{Vs}=\mathrm{k} \cdot \mathrm{SS}^{-\mathrm{n}}$ & 0.9672 & 0.6433 & 0.08 & 0.07 & $2.37 \mathrm{E}-02$ & $6.74 \mathrm{E}-04$ \\
Cho et al. $(\mathrm{a})$ & $\mathrm{Vs}=\mathrm{k} \cdot \mathrm{SS}^{-1} \mathrm{e}^{-\mathrm{n} \cdot \mathrm{SS}}$ & 0.9800 & 0.3927 & 0.14 & 0.47 & $3.63 \mathrm{E}-04$ & $9.49 \mathrm{E}-02$ \\
Cho et al. (b) & $\mathrm{Vs}=(\mathrm{k}-\mathrm{n} \cdot \mathrm{SS})^{4} \mathrm{SS}^{-1}$ & 0.9811 & 0.3715 & 0.03 & 0.43 & $5.63 \mathrm{E}-08$ & $7.05 \mathrm{E}-02$ \\
Richardson \& Zaki & $\mathrm{Vs}=(\mathrm{k}-\mathrm{n} \cdot \mathrm{SS})^{4.65}$ & 0.9918 & 0.1775 & 0.02 & 0.09 & $9.64 \mathrm{E}-07$ & $6.97 \mathrm{E}-05$ \\
\hline
\end{tabular}

\subsection{Influence of ferric chloride addition on the settling characteristics of Carraixet WWTP activated sludge}

97 settling tests were performed to study the influence of the ferric chloride addition on the settling characteristics of the Carraixet WWTP activated sludge. Not only the dose of coagulant was evaluated but also the way the dose was added.

When ferric chloride is added to the water, hydrous ferric oxide (HFO) is rapidly formed and simultaneously phosphates are removed through co-precipitation and phosphates adsorption in the HFOs (Smith et al., 2008). The formed precipitate generates colloids so that the phosphate is trapped inside the floc as its size increases. After the previously described initial rapid phosphorus removal process, there is a slow process of phosphate adsorption in the formed ferric hydroxide flocs (Szabó et al., 2008). However, the precipitation of ferric phosphate occurs only at $\mathrm{pH}$ values below 5 (Smith et al., 2008). At acid $\mathrm{pH}(\mathrm{pH}<4$ - 5) few HFOs are formed, predominating soluble compounds such as the $\mathrm{Fe}^{3+}$ ion, metal hydroxide and metal phosphate complexes with positive charge. The presence of compounds with positive charge also promotes the coagulation of colloidal particles and the formation of larger aggregates that can be retained by the flocs. On the other hand, at alkaline $\mathrm{pH}$ values ( $\mathrm{pH} 7$ to 10), the surface of the HFOs have negative charge and begin to form soluble iron hydroxide complexes with negative charge (Szabó et al., 2008).

In those tests in which ferric chloride was added directly without controlling the $\mathrm{pH}$, a rapid decrease in $\mathrm{pH}$ occurred due to the $\mathrm{Fe}^{3+}$ hydrolysis reactions: $\mathrm{Fe}^{3+}+\mathrm{nH} 2 \mathrm{O} \Leftrightarrow \mathrm{Fe}(\mathrm{OH}) \mathrm{n}^{(3-\mathrm{n})+}+\mathrm{nH}^{+}$(n=1 to 4). Figure $3 \mathrm{a}$ shows that, first the $\mathrm{pH}$ decreases linearly with the dose until a $300 \mathrm{mg} \mathrm{Fe}^{-1}$ dose, or close, is reached and then the $\mathrm{pH}$ stabilizes around 2.6. Caravelli et al. (2010) also showed a strong decrease in $\mathrm{pH}$ with the addition of ferric chloride, down to values between 2 and 3 similarly to the results 
shown in Figure 3a. These low $\mathrm{pH}$ values are not compatible with biological activity in an activated sludge process. In the remaining tests, the $\mathrm{pH}$ was adjusted to values of 6,7 or 8 , or a precipitate, neutralized at $\mathrm{pH} 7$, was added in order to not substantially affect the final $\mathrm{pH}$ value of the activated sludge.

The suspended solids concentration of the sludge increases with the coagulant dose due to the incorporation of nVSS into the sludge. At low $\mathrm{pH}$ values, the nVSS increase is due to the aggregates formed from the colloidal particles, and the $\mathrm{Fe}^{3+}$ and the positively charged complexes adsorbed on the flocs. The sludge nVSS also increase when precipitates are formed with the addition of ferric chloride and when precipitated ferric chloride is directly added to the activated sludge. Figure $3 \mathrm{~b}$ shows the sludge SS increase when ferric chloride with adjustment of $\mathrm{pH}$ was added. Several studies have shown an increase in the activated sludge nVSS due to the chemical precipitation of phosphorus using ferric chloride (Carliell-Marquet et al., 2009; De Gregorio et al., 2011). Asensi et al. (2019b) showed a linear increase in the activated sludge of the nVSS and the dry sludge density with the addition of precipitated ferric chloride.

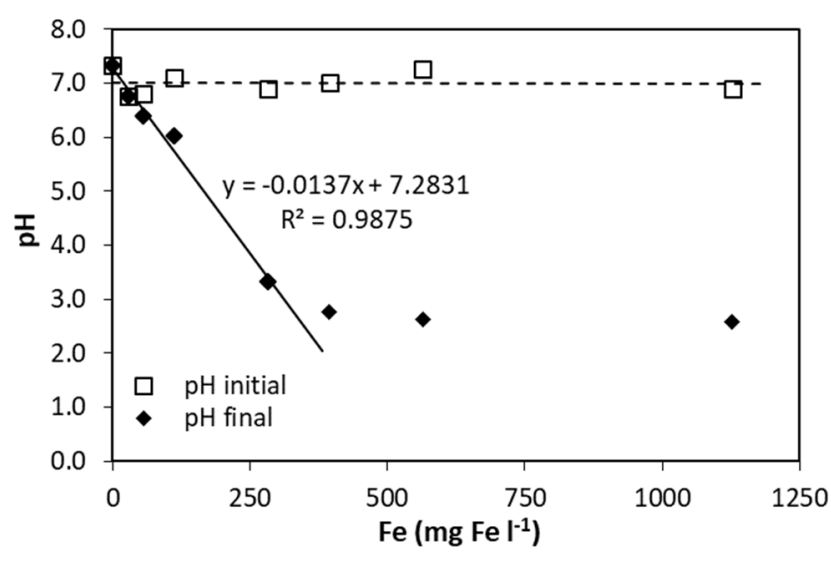

(a)

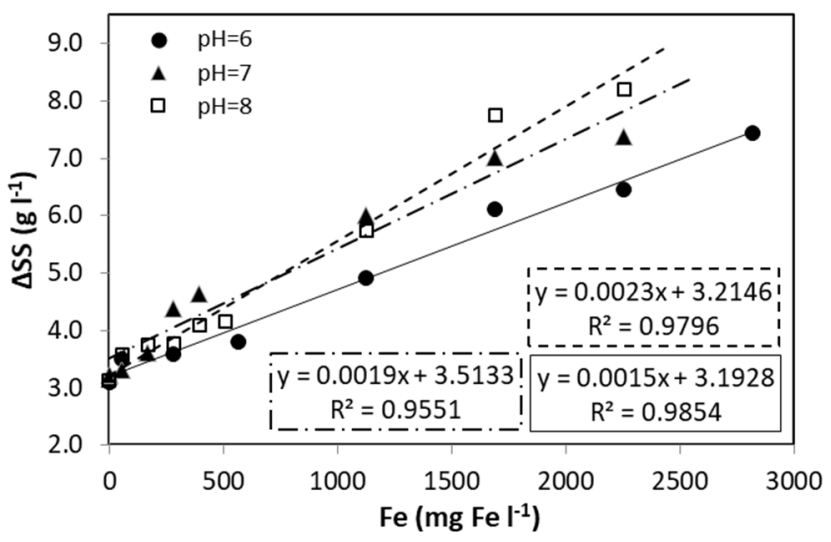

(b)

Figure 3. (a) Impact of direct ferric chloride addition $(\mathrm{Fe})$ with no $\mathrm{pH}$ adjustment, on the $\mathrm{pH}$ of sludge sample $\mathrm{S} 7$ (b) Increase in the sludge suspended solids $(\triangle \mathrm{SS})$ with the added ferric chloride dose (Fe) adjusting the $\mathrm{pH}$ to 6,7 and 8 (sludge samples S10, S14 and S15).

Figure 4 demonstrates the impact of the coagulant on the activated sludge hindered settling velocity. To better visualize this impact, the sedimentation velocity was expressed as Vs/Vso, Vso being the settling velocity of the sludge with no ferric chloride added. This figure shows that the highest improvement in settling velocity was observed when previously precipitated ferric chloride was added (Figure $4 \mathrm{~d}$ ), reaching up to 8 times the velocity with no coagulant addition. It is also worth noticing that excessive coagulant addition is unfavourable because of the higher reagent expense and lower settling velocity increment. A similar pattern was observed when the coagulant was added 
directly without $\mathrm{pH}$ adjustment (Figure 4a). However, this addition form is harmful to the biological process since it causes a drastic reduction of $\mathrm{pH}$ as shown in Figure 3a.

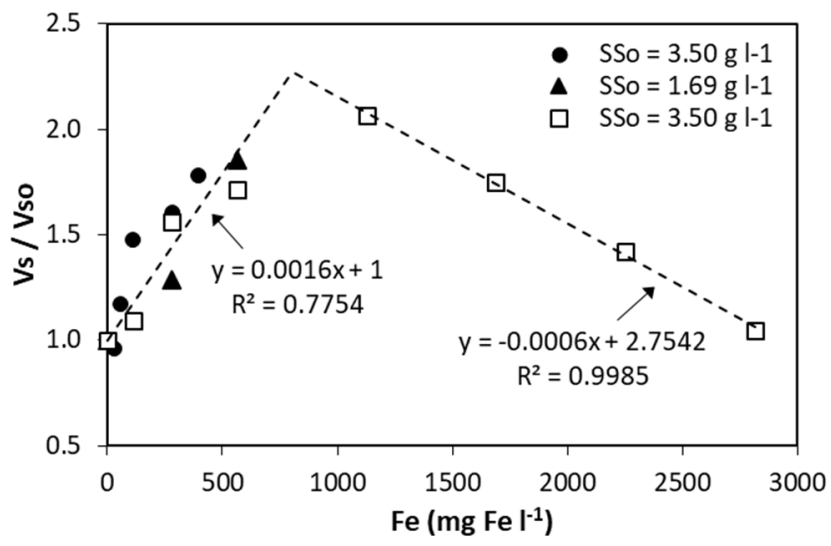

(a)

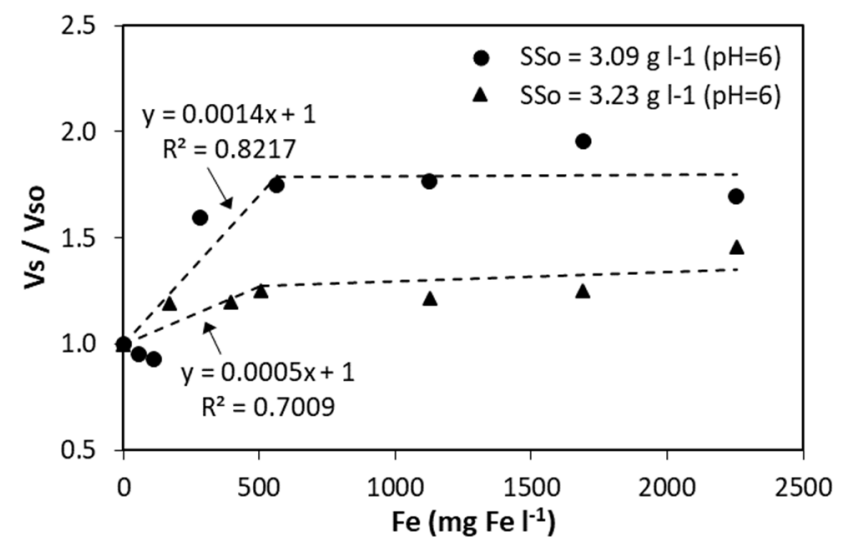

(c)

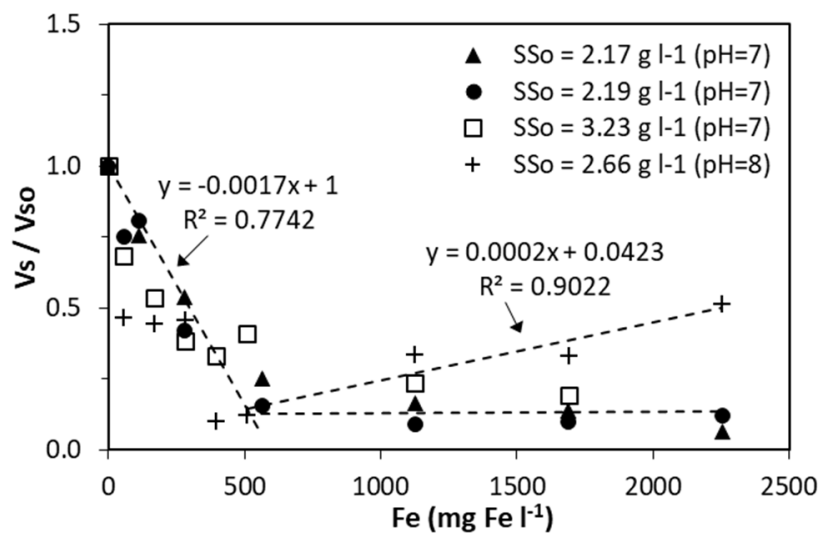

(b)

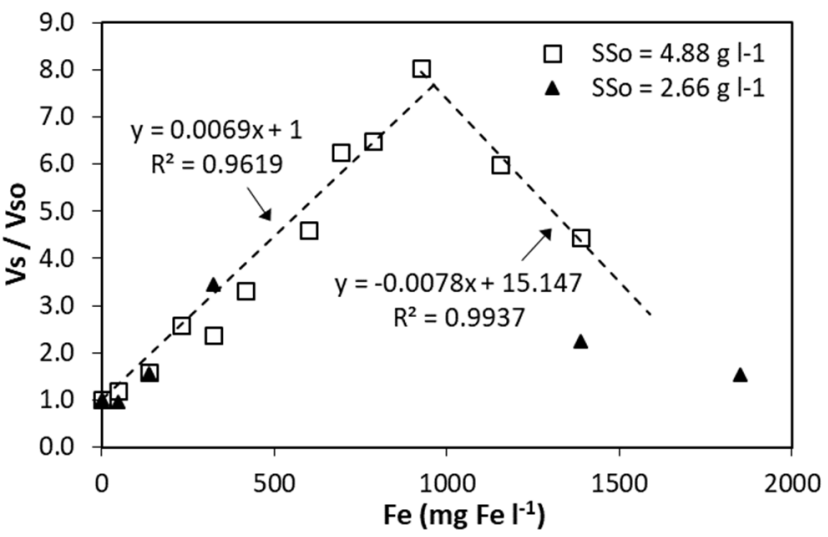

(d)

Figure 4. Impact of coagulant addition form and dose on the hindered settling velocity: (a) direct addition with no $\mathrm{pH}$ adjustment (b) direct addition with $\mathrm{pH}$ adjusted to 7 or 8 (c) direct addition with $\mathrm{pH}$ adjusted to 6 (d) addition of previously precipitated ferric chloride.

When the $\mathrm{pH}$ was adjusted to the desired value during the coagulation process, a different impact on the hindered settling was observed depending on the $\mathrm{pH}$ setting point. At $\mathrm{pH} 7$ and 8 (Figure $3 \mathrm{~b}$ ), the addition of coagulant resulted clearly unfavourable for the hindered settling velocity, experiencing a clear reduction even at a low dose. However, at $\mathrm{pH} 8$ the hindered settling velocity improves slightly at high doses of ferric chloride. At pH 6 an initial improvement of the settling rate with the addition of ferric chloride is observed, while at high coagulant doses the settling velocity does not vary significantly.

To explain the experimental results in Figure 4 it must be considered that the different forms of ferric chloride addition can affect the settling of the activated sludge by improving or worsening the flocculation of the activated sludge and increasing the density of the activated sludge flocs. The 
retention of precipitates or aggregates formed from the colloidal particles in the activated sludge flocs increases the flocs density, thus increasing the sludge settling velocity. This physical effect of increasing the settling velocity of the activated sludge has been extensively studied by means of the addition of inert compounds in the sludge (Vanderhasselt and Verstraete, 1999; Choi et al. 2000; Wiszniowski et al., 2007; Otal et al, 2013; Wells et al. 2015)

The content and composition of extracellular polymeric substances (EPS) in the activated sludge plays an important role in the bioflocculation, sedimentability and dewatering of the activated sludge (Li, 2005; Li et al., 2012; Suresh et al., 2018; Liu et al., 2018). The functional groups in the EPS have a negative global charge, so the EPS chains repel each other. The presence of multivalent cations plays an important role in the neutralization of this charge and helps the flocculation of the sludge by joining the EPS polymers, strengthening the structure of the flocs (Suresh et al., 2018). Li (2005) showed that the ferric chloride addition improves the activated sludge sedimentability and increases the iron proportion in the EPS favouring the union between functional charged groups of the EPS.

Since the $\mathrm{pH}$ rapidly lowers when the ferric chloride is added without adjusting the $\mathrm{pH}$, the presence of $\mathrm{Fe}^{3+}$ improves the sludge flocculation by neutralizing the charge and binding the functional groups of the EPS. In Figure 4a, the sludge settling velocity is improved by forming more compact flocs and increasing the flocs density by retaining the aggregates formed by the destabilized colloidal particles and the precipitated ferric phosphate. At high coagulant doses, the $\mathrm{Fe}^{3+}$ excess can invert the colloidal particles charges preventing the particles from binding. Moreover, the excess of $\mathrm{Fe}^{3+}$ could probably also damage the flocs flocculation process by negatively affecting the EPS. These changes can explain the decrease in Vs observed in Figure 4a.

When ferric chloride is added by adjusting the $\mathrm{pH}$ to 6 (Figure 4c), the presence of compounds with positive charge favours the destabilization of the colloidal particles, so that the retention of the formed aggregates together with the precipitates increase the flocs density and the settling velocity. In this case, there is no a decrease in the settling velocity probably because there is no adverse effect in the flocculation process since there is no an excess of $\mathrm{Fe}^{3+}$ at $\mathrm{pH} 6$ (as previously indicated $\mathrm{Fe}^{3+}$ predominates at $\mathrm{pH}<4-5$ ).

The activated sludge hindered settling velocity decreases with increasing the SS when no ferric chloride is added. This decrease is due to the fact that an increase of the SS supposes a decrease in the sludge volumetric fraction $(\mathrm{Fv})$, defined as the ratio between the volume of the SS with respect to 
the total volume of the sludge. The decrease of Fv leads to a reduction of the mean distance between flocs, increasing the hydrodynamic drag forces that originate the decrease of the hindered settling velocity. When the aggregates formed by colloidal particles or by precipitates are retained by the flocs, the flocs density and the Vs increase. But if the aggregates are not retained by the flocs, the volume fraction, and thus Vs, decrease.

In Figure $4 \mathrm{~b}$ where the $\mathrm{pH}$ is adjusted to 7 and 8 , soluble and precipitated compounds with negative charge are produced (Szabó et al., 2008). If the formed precipitates are not retained by the flocs due to the repulsion generated by the negative charge of the flocs, the increase of the SS with the addition of the coagulant will produce a decrease in Fv and thus a decrease in Vs. If part of the precipitates were retained by the flocs or if the soluble compounds were absorbed by the flocs, then the flocs negative charge would increase, worsening the flocculation process and consequently the activated sludge sedimentability.

When a ferric chloride precipitate formed by $\mathrm{Fe}(\mathrm{OH})_{3}$ is added (Figure 4d), the retention of such precipitate increases the flocs density and so the Vs. Asensi et al. (2019b) showed a linear increase in the density of the flocs with the addition of precipitated ferric chloride in the dose range which corresponds to increasing Vs in Figure 4d. Flocs will have a maximum capacity to retain the added precipitate, so at high doses of precipitate, the amount not being retained by the flocs will cause the decrease of the Fv, thus decreasing the Vs.

Several studies have shown an improvement in the activated sludge sedimentability with the addition of ferric chloride using standard doses for phosphorus removal by chemical precipitation (Oikonomidis et al., 2009; De Gregorio et al. 2010). Li (2005) using higher ferric chloride doses reported a worsening in the sedimentability of the activated sludge, due to a weakening in the flocculation process that resulted in dispersed flocs.

Since soluble phosphate removal is a typical application of the use of ferric chloride in WWTPs, this parameter was measured in several settling tests before and after the addition of the coagulant. Figure 5 shows the favourable response of the ferric chloride dose on phosphate removal. Notice that at very low doses (Figure 5a) the concentration of $\mathrm{PO}_{4}{ }^{3-}-\mathrm{P}$ fell below $1 \mathrm{mg} \mathrm{P}^{-1}$ when the $\mathrm{pH}$ was adjusted during the coagulation process, while when previously precipitated ferric chloride was added, noticeable higher doses were required to achieve the same phosphate reduction. 
When adding ferric chloride by adjusting the $\mathrm{pH}$, the rapid mechanism of coprecipitation and phosphate adsorption predominates in the HFOs formed. Figure 5a shows that phosphorus was rapidly eliminated with a low dose of iron. However, the phosphates elimination was not efficient when high concentrations of ferric chloride were added. Smith et al. (2008) consider that when the molar ratio between iron and phosphates is high, the phosphorus removal efficiency decreases since there is a higher probability that HFO particles containing iron interact with each other than with phosphorus.

When precipitated ferric chloride is added, the slower mechanism of phosphorus removal by adsorption predominates. Figure $5 \mathrm{~b}$ shows that for the same iron dose, the phosphate elimination performance is lower than when ferric chloride was added by adjusting the $\mathrm{pH}$. This is because only the surface of the HFO is available for the adsorption of phosphorus since much of the internal oxygen atoms are not available to bind with the phosphate. Although HFO flocs are porous, inner adsorption is limited by diffusion of phosphate (Smith et al., 2008). Thistleton et al. (2002) also reported that to eliminate a similar amount of phosphorus, a higher dose of previously precipitated iron hydroxide than of ferric chloride was needed.

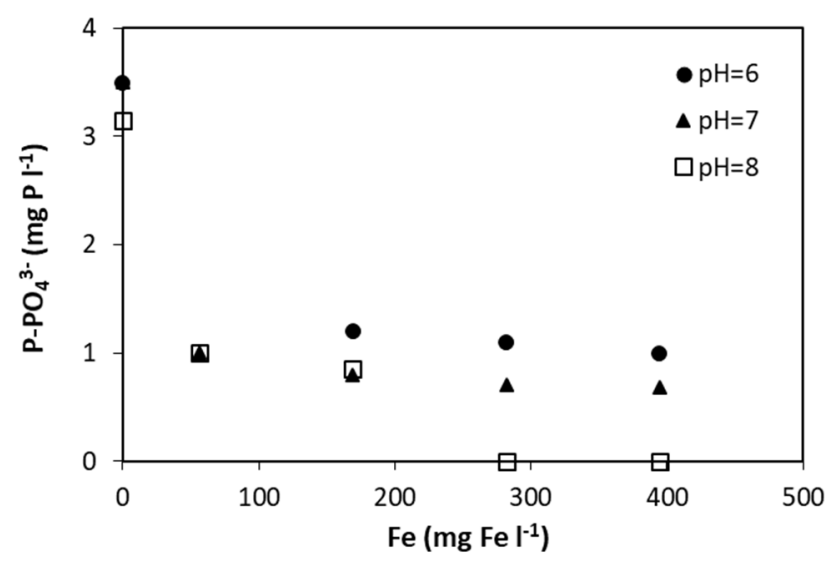

(a)

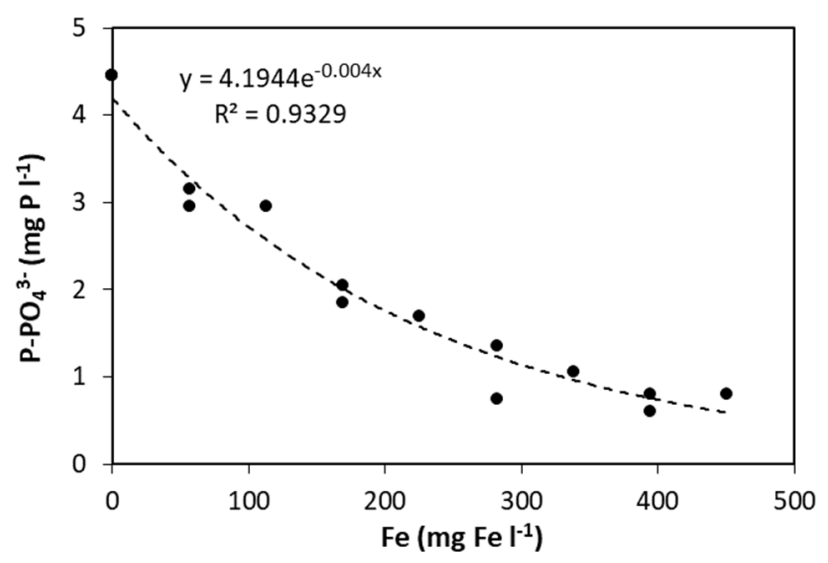

(b)

Figure 5. Impact of ferric chloride addition on phosphate removal: (a) direct addition with pH adjusted to 6,7 or 8 (b) addition of previously precipitated ferric chloride.

The remarkable improvement in the activated sludge hindered settling velocity and the soluble phosphate removal, made the dosing of precipitated and neutralized ferric chloride interesting to meet the effluent discharge legal requirements in cases of poor plant operation or of legal imposition of stringent effluent quality limits. It would be a low-cost option in contrast to the use of structural solutions that require significant investment costs and construction time such as the implementation of sand filters or membranes as tertiary treatment. 


\subsection{Modelling the activated sludge hindered settling velocity with the addition of precipitated ferric chloride}

Based on the previous results (Figure 4), 37 new settling tests were performed in a limited range of precipitated ferric chloride doses for modelling purposes. It was observed a linear increase of SS with the dose (Asensi et al. 2019b) as expected since the precipitate is formed by iron hydroxides, thus, the added solids are non-volatile suspended solids.

In the experimental tests carried out, the dose of added iron coincides with the iron concentration in the sludge ( $\mathrm{Fe}$ ). However, when the precipitate was added into an activated sludge process biological reactor, the precipitated ferric chloride concentration does not coincide with the added precipitate dose due to the sludge recirculation from the secondary settler. The models proposed in this section for hindered settling velocity will be valid since the models used for the design and simulation of an activated sludge process calculate the sludge inert SS concentration taking into account the recirculation effect. In order to use the proposed models in the operation of a secondary settler without using a simulation model, for example, by making use of a state point graph, the precipitate concentration in the sludge $(\mathrm{Fe})$ in steady state, can be estimated from the added iron dose ( $\mathrm{Fe}$ dose). That is, the precipitate concentration can be calculated as Fe $=\mathrm{Fe}$ dose $\cdot \mathrm{SRT} / \mathrm{HRT}$, where SRT is the solids retention time and HRT the hydraulic residence time of the sludge reactor.

Figure 6 reveals the impact on the activated sludge hindered settling velocity of the ferric chloride precipitate addition (in the range $0-500 \mathrm{mg} \mathrm{Fe}^{-1}$ ). This figure evidences that the hindered settling velocity varies linearly with the precipitate's concentration.

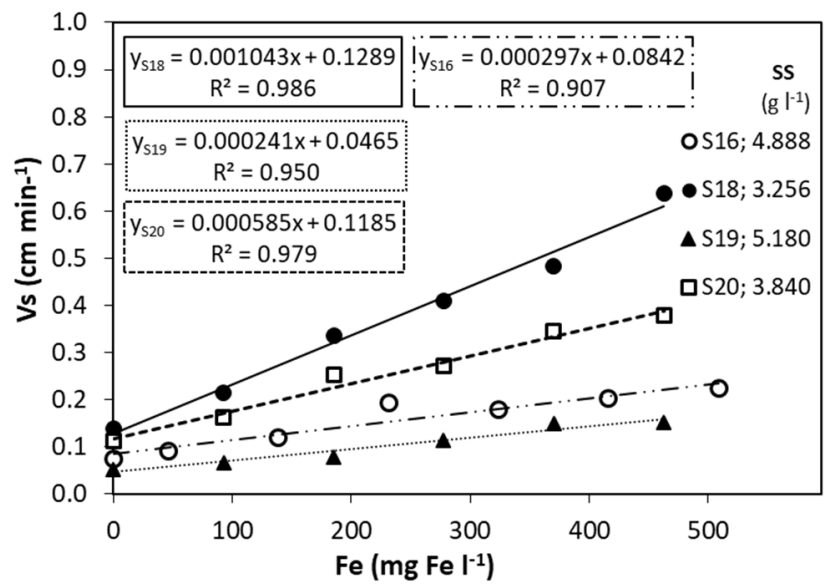

(a)

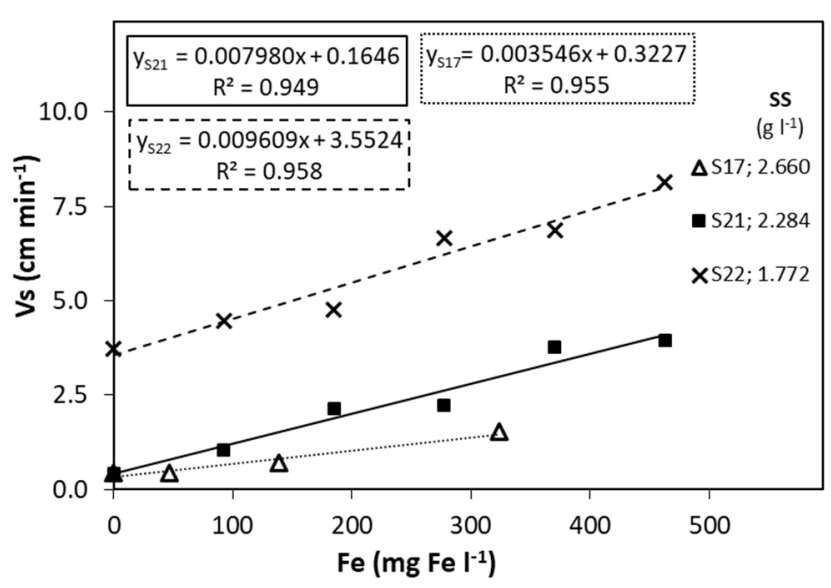

(b)

Figure 6. Impact of previously precipitated ferric chloride addition ( $\mathrm{Fe}$ ) on the activated sludge hindered settling velocity (Vs). For reasons of data scale and to facilitate visualization, the seven fittings have been plotted in two separate graphs. 
In other studies, it was also found an improvement in the activated sludge sedimentability with the addition of some inert material, but its effect on the settling velocity has not been studied in detail. For example, a decrease in the activated sludge SVI was observed with the addition of bentonite (Wiszniowski et al., 2007), synthetic zeolite (Otal et al., 2013) or loess (Wells et al., 2015). Vanderhasselt and Verstraete (1999) also showed a linear increase in the activated sludge settling velocity with the addition of talc in an industrial WWTP and Choi and Chung (2000) showed a linear increase with the addition of humus soil in an urban WWTP. In all these studies, the effect of the SS concentration in the linear settling velocity increment was not analyzed, nor the joint effect of the added compound dose and the SS in the activated sludge hindered settling velocity.

As shown in Figure 6, the fitted slope obtained in the settling tests was different for each sludge sample (S16-S22). Since each sample had a different original suspended solids concentration (SSo), the slope of each linear fit was plotted against the SSo of the corresponding sludge sample (see Figure 7). Figure 7 shows a clear exponential decline, indicating a more limited improvement of the settling velocity (lower slope of the linear fit) with the increase of the SSo of the sludge sample. This can be due to the fact that the higher the suspended solids concentration in the sludge sample, the lower the amount of iron available per unit of suspended solids (i.e., the ratio Fe/SSo in the sludge sample is lower). The fitted equations allow determining the hindered settling velocity for different doses of precipitated ferric chloride added as $\mathrm{Vs}=\mathrm{Vs}(\mathrm{SSo})+0.0721 \mathrm{exp}(-1.15 \cdot \mathrm{SSo}) \cdot \mathrm{Fe}$, being the SSo the suspended solids concentration of the original activated sludge sample (i.e., with no precipitated ferric chloride added), $\mathrm{Vs}(\mathrm{SSo})$ the settling velocity at SSo, and Fe the concentration of precipitate in $\mathrm{mg}$ $\mathrm{Fe}^{-1}$. Although this empirical model can be useful and valid for practical purposes and for process operation, it cannot be used directly on standard settling models implemented in commercial software.

To be able to implement the gained insight in commercial tools and model the zonal sedimentation pattern, the hindered settling velocity was fitted with the two mathematical models that better represented the settling behaviour of the Carraixet WWTP activated sludge, and in turn, their parameters were related to the precipitated ferric chloride concentration via empirical equations.

As previously mentioned, the suspended solids concentration linearly increased with the precipitated ferric chloride concentration. For this reason and in order to make independent the effect of both variables: the sludge sample initial suspended solids concentration and the amount of added precipitated ferric chloride (i.e., the iron concentration), the hindered settling velocity was represented versus SSo for each iron concentration $\left(0,92.5,185.0,370.0\right.$ and $\left.462.5 \mathrm{mg} \mathrm{Fe}^{-1}\right)$. Table 4 shows the 
performance of Vesilind's exponential and Richardson and Zaki models to describe the hindered settling velocity of the Carraixet WWTP activated sludge when previously precipitated ferric chloride was added. This table shows that, although both models describe quite well the zonal settling behaviour $\left(\mathrm{R}^{2}>0.9761\right.$ and MSE $\left.<0.2481 \mathrm{~cm}^{2} \mathrm{~min}^{-2}\right)$, Richardson and Zaki model gave statistical significant parameters ( $\mathrm{p}$-value $<0.01$ ) in all tests.

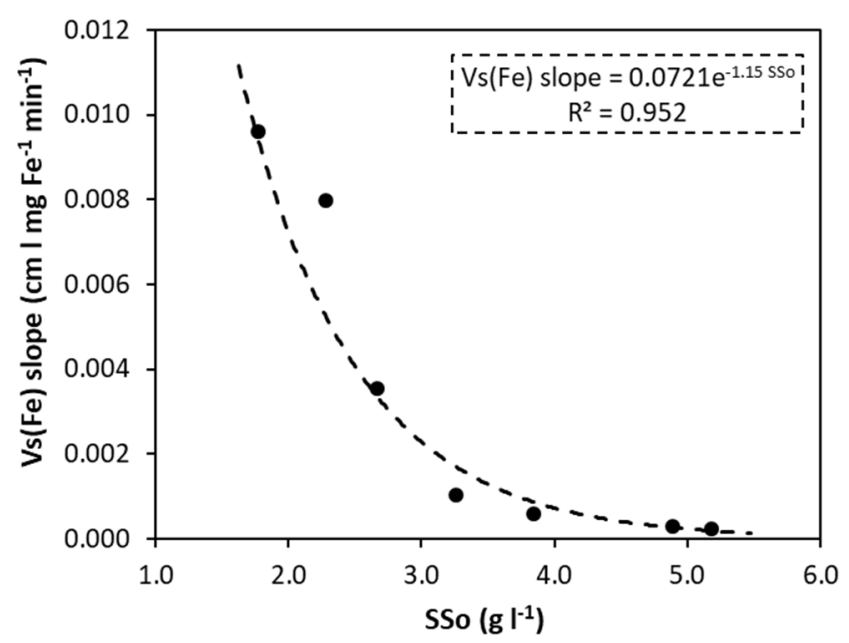

Figure 7. Influence of the sludge sample suspended solids concentration (SSo) on the settling velocity improvement (i.e., slope of each linear fitting in Figure 6) due to the addition of precipitated ferric chloride.

Table 4. Performance of Vesilind's exponential and Richardson and Zaki models to describe the hindered settling velocity as a function of the initial suspended solids concentration. The values of the table correspond to the fit of the settling tests

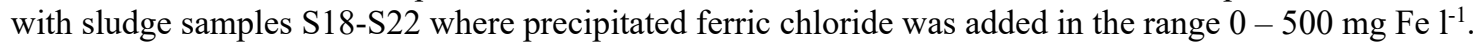

\begin{tabular}{|c|c|c|c|c|c|c|c|c|c|}
\hline \multirow[t]{2}{*}{ Model } & \multirow{2}{*}{$\begin{array}{c}\text { Iron } \\
\left(\mathrm{mg} \mathrm{Fe} \mathrm{l}^{-1}\right)\end{array}$} & \multicolumn{3}{|c|}{ k-parameter } & \multicolumn{3}{|c|}{ n-parameter } & \multirow[t]{2}{*}{$\mathbf{R}^{2}$} & \multirow{2}{*}{$\begin{array}{c}\text { MSE } \\
\left(\mathrm{cm}^{2} \mathrm{~min}^{-2}\right)\end{array}$} \\
\hline & & $\mathbf{k}^{*}$ & std* & p-value & $1 * *$ & std** & p-value & & \\
\hline \multirow{5}{*}{$\begin{array}{l}\text { Vesilind's } \\
\text { exponential } \\
\text { Vs }=\mathrm{k} \cdot \mathrm{e}^{-\mathrm{nSS}}\end{array}$} & 0 & 246.2 & 105.6 & $1.5 \mathrm{E}-01$ & 2.244 & 0.242 & $1.1 \mathrm{E}-02$ & 0.9995 & 0.0020 \\
\hline & 92.5 & 137.5 & 44.9 & $9.2 \mathrm{E}-02$ & 1.933 & 0.183 & 8.9 E-03 & 0.9992 & 0.0029 \\
\hline & 185.0 & 81.3 & 10.9 & $4.9 \mathrm{E}-03$ & 1.599 & 0.071 & 1.9 E-04 & 0.9986 & 0.0045 \\
\hline & 370.0 & 80.9 & 22.8 & $3.8 \mathrm{E}-02$ & 1.382 & 0.147 & $2.6 \mathrm{E}-03$ & 0.9913 & 0.0607 \\
\hline & 462.5 & 75.2 & 31.1 & $9.5 \mathrm{E}-02$ & 1.237 & 0.213 & $1.0 \mathrm{E}-02$ & 0.9761 & 0.2481 \\
\hline \multirow{3}{*}{$\begin{array}{c}\text { Richardson } \\
\text { \& Zaki }\end{array}$} & 0 & 2.194 & 0.077 & $1.2 \mathrm{E}-03$ & 0.454 & 0.043 & 8.8 E-03 & 0.9990 & 0.0040 \\
\hline & 92.5 & 2.113 & 0.070 & $1.0 \mathrm{E}-03$ & 0.413 & 0.039 & $8.6 \mathrm{E}-03$ & 0.9984 & 0.0057 \\
\hline & 185.0 & 2.125 & 0.051 & $3.1 \mathrm{E}-05$ & 0.411 & 0.027 & 5.9 E-04 & 0.9969 & 0.0099 \\
\hline \multirow[t]{2}{*}{$\mathrm{Vs}_{\mathrm{s}}=(\mathrm{k}-\mathrm{nSS})^{4.65}$} & 370.0 & 2.206 & 0.055 & $3.3 \mathrm{E}-05$ & 0.389 & 0.028 & 7.8 E-04 & 0.9959 & 0.0287 \\
\hline & 462.5 & 2.224 & 0.091 & $1.5 \mathrm{E}-04$ & 0.364 & 0.046 & $4.1 \mathrm{E}-03$ & 0.9863 & 0.1419 \\
\hline
\end{tabular}

* $\mathrm{cm} \mathrm{min}{ }^{-1}$ in Vesilind's exponential model and $\left(\mathrm{cm} \mathrm{min}^{-1}\right)^{1 / 4.65}$ in Richardson and Zaki model.

** $1 \mathrm{~g}^{-1}$ in Vesilind's exponential model and $\left(\mathrm{cm} \mathrm{min}^{-1}\right)^{1 / 4.65} \mathrm{~g}^{-1}$ in Richardson and Zaki model.

The original Richardson and Zaki model is given in the form $\mathrm{Vs}=\mathrm{Vo} \cdot(1-\mathrm{j} \cdot \mathrm{SS})^{4.65}$. One of the advantages of using this model is that the Vo and $\mathrm{j}$ parameters have physical meaning. The parameter 
Vo represents the terminal settling velocity of the flocs at low Reynolds numbers (i.e., laminar flow conditions), through the Stokes law. Whereas the parameter $\mathrm{j}$ represents the quotient between the aggregate volume index and the dry sludge density ( $\rho s)$. The aggregate volume index is defined as the quotient between the flocs volume and volume of solids contained in the flocs. A different parametrization of the model $\left(\mathrm{Vs}=(\mathrm{k}-\mathrm{n} \cdot \mathrm{SS})^{4.65}\right)$ was used to perform the regressions (Tables 3 and 4) since non-linear regression methods used by Mathematica did not work correctly with the original parametrization. From parameters $\mathrm{k}$ and $\mathrm{n}$, obtained from Richardson and Zaki model regressions, $\mathrm{Vo}_{\mathrm{o}}=\mathrm{k}^{4.65}$ and $\mathrm{j}=\mathrm{n} / \mathrm{k}$ were calculated.

To obtain a useful model for the zonal sedimentation when precipitated and neutralized ferric chloride is added, the parameters of the settling models should be related to the iron concentration. For this purpose, two empirical equations were proposed and fitted. These models described reasonably well the parameters' variation with the concentration of ferric chloride, as shown in Figure 8.

Figures $8 \mathrm{a}$ and $8 \mathrm{~b}$ show that the Vo parameter in Richardson and Zaki model increases linearly, while the $\mathrm{j}$ parameter decreases linearly with the iron concentration. The linear relationship is described as $\mathrm{Vo}_{0}=\mathrm{Vo}_{0}+\mathrm{a} \cdot \mathrm{Fe}$ and $\mathrm{j}=\mathrm{j}_{0}-\mathrm{b} \cdot \mathrm{Fe}$, where $\mathrm{Vo}_{0}$ and $\mathrm{j}_{0}$ represent the terminal settling velocity of the flocs and the $j$ value of the original activated sludge with no added precipitate. The linear increase of nVSS with the precipitate concentration causes a linear increase in flocs and dry sludge density due to the integration of the precipitate into the flocs. The terminal settling velocity of the flocs is calculated using Stokes law as $V_{0}=(\rho f-\rho) d_{f}^{2} / 18 \mu$, being $\rho f$ the flocs density and $d_{f}$ the flocs equivalent diameter. Thus, the linear increase in flocs density leads to the linear increase in Vo. On the other hand, the linear decrease of $\mathrm{j}$ is explained by the dry sludge density increase and by the volume increase of the solids contained in flocs, caused by the addition and subsequent absorption of precipitate into the flocs. These results agree with those of Jones and Schuler (2012), who showed that an increase in the nVSS content of the activated sludge causes an increment in the flocs density, and that such increase of density improves the sedimentability of the sludge.

The exponential model parameters $\mathrm{k}$ and $\mathrm{n}$ decrease with the iron concentration until reaching a constant value (Figures $8 \mathrm{c}$ and $8 \mathrm{~d}$ ). To describe the precipitate's addition effect the following equations were used: $\mathrm{k}=\mathrm{k}_{0}-\left(\mathrm{k}_{0}-\mathrm{k}_{\mathrm{f}}\right) \mathrm{Fe} /\left(\mathrm{ks}_{\mathrm{S}}+\mathrm{Fe}\right)$ and $\mathrm{n}=\mathrm{n}_{0}-\left(\mathrm{n}_{0}-\mathrm{n}_{\mathrm{f}}\right) \mathrm{Fe} /\left(\mathrm{n}_{\mathrm{s}}+\mathrm{Fe}\right)$, where $\mathrm{k}_{0}$ and $\mathrm{n}_{0}$ represent the $\mathrm{k}$ and $\mathrm{n}$ values with no added precipitate, $\mathrm{k}_{\mathrm{f}}$ and $\mathrm{n}_{\mathrm{f}}$ represent the final $\mathrm{k}$ and $\mathrm{n}$ values obtained from large precipitate concentration, and $\mathrm{ks}_{\mathrm{s}}$ and $\mathrm{n}_{\mathrm{s}}$ the semisaturation constants used to describe the decrease of $\mathrm{k}$ and $\mathrm{n}$ with Fe. The exponential model is an empirical model whose parameters do not 
have a clearly defined physical meaning, and it also requires of a greater number of parameters to describe the addition of a precipitate effect. However, it has the advantage of being a model widely used to describe the activated sludge hindered settling velocity.

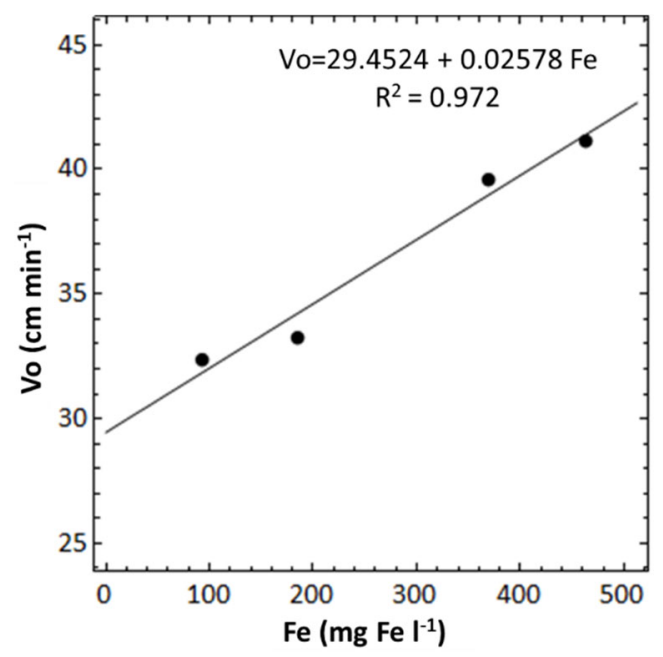

(a)

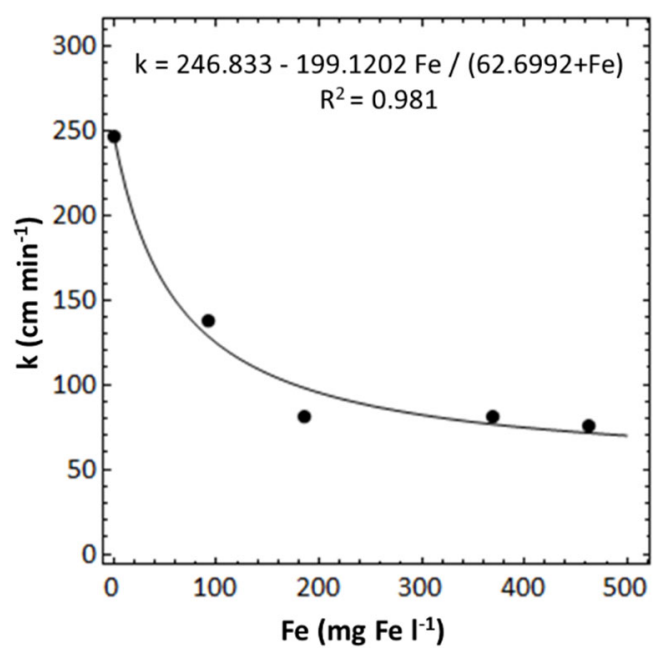

(c)

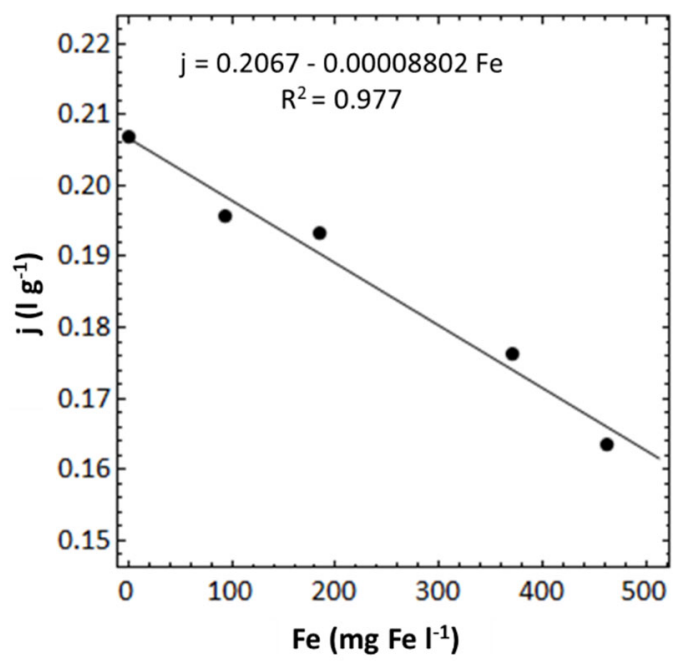

(b)

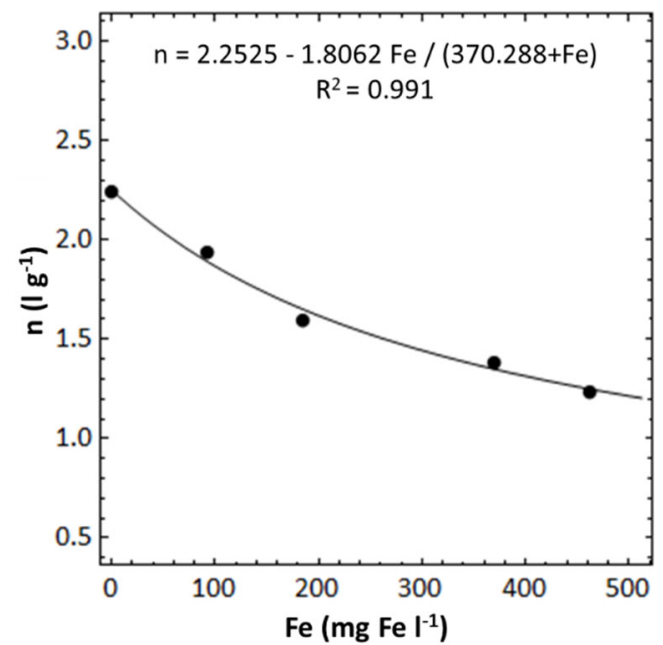

(d)

Figure 8. Relationship between the mathematical model parameters and the precipitated ferric chloride concentration (Fe): (a) Vo and (b) $\mathrm{j}$ in Richardson and Zaki model $\left(\mathrm{Vo}_{\mathrm{o}}=\mathrm{k}^{4.65}\right.$ and $\left.\mathrm{j}=\mathrm{n} / \mathrm{k}\right)$. (c) $\mathrm{k}$ and (d) $\mathrm{n}$ in Vesilind's exponential model.

The results obtained for parameter $\mathrm{n}$ in the exponential model are compatible with those obtained by Schuler and Jang (2007). Schuler and Jang (2007) performed settling tests by adding microspheres into the activated sludge to study the effect of an increment in flocs density in the parameters of the exponential model. They obtained that, when increasing the flocs density, the parameter $\mathrm{n}$ of the exponential model descended initially, until reaching a final constant value. However, parameter $\mathrm{k}$ after suffering an initial descent, increased again. 
The disagreement between the two studies for the parameter k, may be due to the existence of an additional effect to that of the increase of flocs density, such as a change of flocs structure due to the addition of coagulant (Li, 2005; Li et al., 2012). Asensi et al. (2019b) showed that the median of the flocs equivalent diameter and the fractal dimension relating the flocs area to their perimeter $\left(\mathrm{Df}_{\mathrm{A}-\mathrm{L}}\right)$ decrease both with the precipitated ferric chloride dose. They also showed that the hindered settling velocity was related to the $\mathrm{Df}_{\mathrm{A}-\mathrm{L}}$. New studies are needed to obtain a deeper knowledge of the relationship between the parameters in both models, that is, the exponential model and Richardson and Zaki model, and of other activated sludge floc properties that can be affected with the addition of coagulant (size, fractal dimensions, etc.). It is also necessary to study model extensions using different inert materials to improve the activated sludge hindered settling velocity.

The models to describe the activated sludge hindered settling velocity as a function of the SS concentration with no added precipitate ( $\mathrm{SSo})$ and as a function of the precipitate concentration $(\mathrm{Fe})$ proposed in this paper are given in equations 1 and 2. These models can also be expressed as a function of the SS concentration after adding the precipitate, considering that the SS grow linearly with Fe.

Richardson and Zaki model: $\quad \mathrm{Vs}=\left(\mathrm{Vo}_{0}+\mathrm{a} \cdot \mathrm{Fe}\right)\left(1-\left(\mathrm{j}_{0}-\mathrm{b} \cdot \mathrm{Fe}\right) \mathrm{SSo}\right)^{4.65}$

Vesilind's exponential model: $\quad \mathrm{Vs}=\left(\mathrm{k}_{0}-\frac{\left(\mathrm{k}_{0}-\mathrm{k}_{\mathrm{f}}\right) \mathrm{Fe}}{\mathrm{k}_{\mathrm{s}}+\mathrm{Fe}}\right) \mathrm{e}^{-\left(\mathrm{n}_{0}-\frac{\left(\mathrm{n}_{0}-\mathrm{n}_{\mathrm{f}}\right) \mathrm{Fe}}{\mathrm{n}_{\mathrm{s}}+\mathrm{Fe}}\right) \mathrm{sso}}$

Figures $9 \mathrm{a}$ and $9 \mathrm{~b}$ show the predicted values for the hindered settling velocity (Predicted Vs) using the proposed models (Eq. 1 and 2) and the calibrated parameters for the Carraixet WWTP (Figure 8), versus the experimentally measured settling velocity (Vs). Both models describe correctly Vs, the exponential model being slightly better $\left(\mathrm{R}^{2}=0.973, \mathrm{MSE}=0.153 \mathrm{~cm}^{2} \mathrm{~min}^{-2}\right)$ than Richardson and Zaki model $\left(\mathrm{R}^{2}=0.968, \mathrm{MSE}=0.182 \mathrm{~cm}^{2} \mathrm{~min}^{-2}\right)$.

These results can be easily incorporated to the commercial tools to improve the predictive capacity of the WWTP mathematical model. Given that plant-wide modelling is becoming a standard practice (i.e., interaction between the models of all biological and physicochemical processes involved), and the use of coagulants in WWTPs is frequent, the experimental results obtained are relevant since they allow to consider the influence of the addition of precipitated ferric chloride (for P removal and sludge sedimentability improvement) on the activated sludge settling properties. Notice that chemical 
precipitation models determine the precipitate formed, and thus, the physical effect of density increase on the settling velocity can be considered, but not the coagulant's chemical effect. Further research is needed to quantify and model this chemical effect.

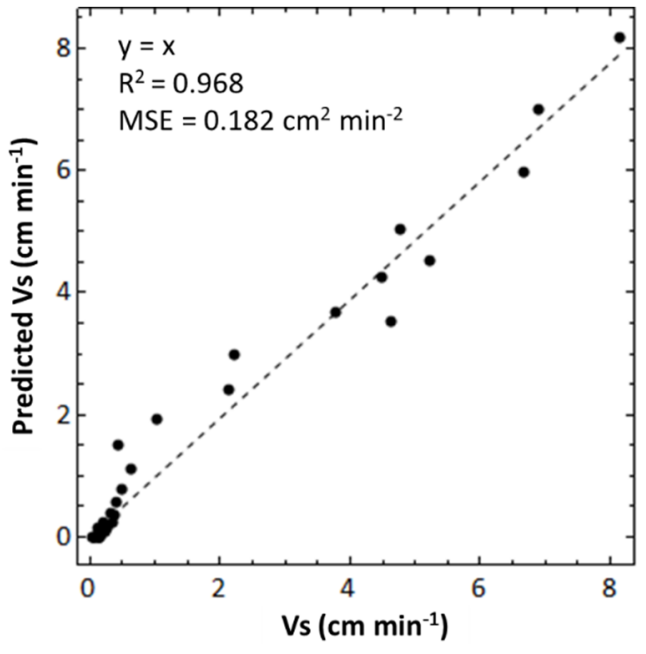

(a)

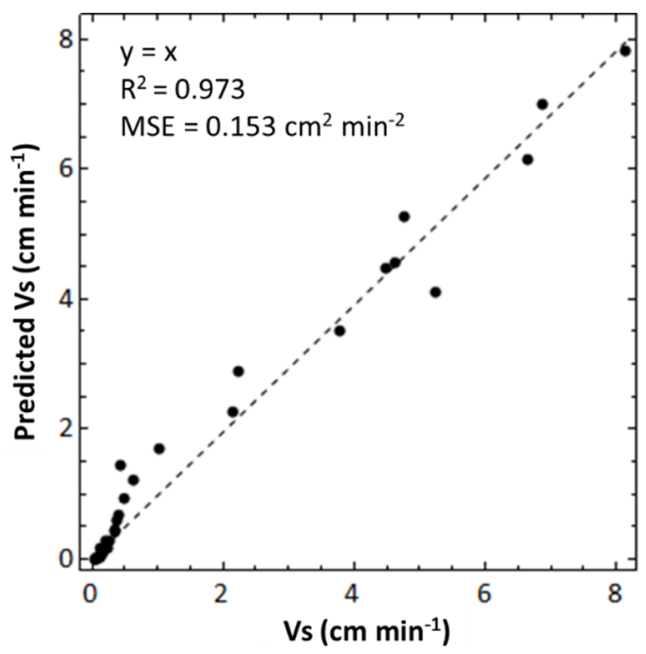

(b)

Figure 9. Experimental hindered settling velocity in the 37 settling tests versus predicted values of hindered settling velocity using: (a) Richardson and Zaki model (b) Vesilind's exponential model.

\section{CONCLUSIONS}

In this work, interesting experimental results on the effect of ferric chloride addition on the activated sludge settling characteristics of a full-scale WWTP are presented, analysed and discussed. The main conclusions that can be drawn from this study are:

- Direct addition of $\mathrm{FeCl}_{3}$ to the activated sludge without $\mathrm{pH}$ adjustment improved the hindered settling velocity. However, the addition of the coagulant produced, at high coagulant concentrations, a sharp decrease in the $\mathrm{pH}$ making the biological process unviable.

- The impact on the hindered settling velocity of $\mathrm{FeCl}_{3}$ addition with $\mathrm{pH}$ adjustment depended on the $\mathrm{pH}$ set-point.

- Phosphorus removal required a higher coagulant dose when previously precipitated ferric chloride was added than when $\mathrm{FeCl}_{3}$ was added with the $\mathrm{pH}$ adjusted to the desired set-point during the coagulation process.

- The addition of previously neutralized and precipitated ferric chloride leads to the largest increase of the activated sludge hindered settling velocity (up to 8 folds). It was observed a linear increment in the settling velocity with the coagulant dose. The slope of the obtained linear relationship decreases exponentially with the activated sludge initial SS concentration. 
- Richardson and Zaki model and the Vesilind's exponential model were able to reproduce the hindered settling velocity when precipitated ferric chloride was added. Two empirical equations were proposed and fitted to relate both models parameters to the precipitate concentration.

- Richardson and Zaki model allows to explain the increment in the hindered settling velocity with the addition of precipitated ferric chloride as a consequence of the increase of flocs and dry sludge density resulting from the incorporation of the precipitate into the activated sludge floc structure.

\section{ACKNOWLEDGEMENTS}

This research work did not receive any specific grant from funding agencies in the public, commercial, or not-for-profit sectors.

\section{REFERENCES}

APHA (2012). American Public Health Association/American Water Works Association/Water Environmental Federation. Standard Methods for the Examination of Water and Wastewater, 22nd edition, Washington DC, USA.

Asensi E., Alemany E., Seco A., Ferrer J. (2019a). Characterization of activated sludge settling properties with a sludge collapse-acceleration stage. Separation and Purification Technology 209, 32-41. doi: 10.1016/j.seppur.2018.07.006.

Asensi, E., Zambrano, D., Alemany, E., \& Aguado, D. (2019b). Effect of the addition of precipitated ferric chloride on the morphology and settling characteristics of activated sludge flocs. Separation and Purification Technology, 227, 115711. https://doi.org/10.1016/j.seppur.2019.115711.

Barat R., Serralta J., Ruano M.V., Jiménez E., Ribes J., Seco A., Ferrer J. (2013). Biological Nutrient Removal Model No 2 (BNRM2): A general model for Wastewater Treatment Plants. Water Science and Technology, 67(7):1481-1489. doi:10.2166/wst.2013.004.

Bratby J. (2016). Coagulation and flocculation in water and wastewater treatment, Third Edit, IWA Publishing, London. doi:ISBN 9781780407494.

Burger W., Krysiak-Baltyn K., Scales P.J., Martin G.J.O., Stickland A.D., Gras S.L. (2017). The influence of protruding filamentous bacteria on floc stability and solid-liquid separation in the activated sludge process. Water Research, 123, 578-585. doi: 10.1016/j.watres.2017.06.063.

Caravelli, A. H., Contreras, E. M., \& Zaritzky, N. E. (2010). Phosphorous removal in batch systems using ferric chloride in the presence of activated sludges. Journal of hazardous materials, 177(1-3), 199-208. doi: 10.1016/j.jhazmat.2009.12.018.

Carliell-Marquet C., Smith J., Oikonomidis I., \& Wheatley A. (2010). Inorganic profiles of chemical phosphorus removal sludge. Proceedings of the Institution of Civil Engineers - Water Management 2010 163(2), 65-77. doi: 10.1680/wama.2010.163.2.65.

Chen G.W., Chang I.L., Hung W.T., Lee D.J. (1996). Regimes for zone settling of waste activated sludges. Water Research, 30 (8), 1844-1850. doi: 10.1016/0043-1354(95)00322-3.

Choi Y.G., Chung T.H. (2000). Effects of humus soil on the settling and dewatering characteristics of activated sludge. Water Science and Technology, 42(9), 127-134. doi: 10.2166/wst.2000.0187.

Christensen M.L., Keiding K., Nielsen P.H., Jørgensen M.K. (2015). Dewatering in biological wastewater treatment: A review. Water Research, 82, 14-24. doi: 10.1016/j.watres.2015.04.019. 
De Gregorio C., Caravelli A.H., Zaritzky N.E. (2010). Performance and biological indicators of a laboratory-scale activated sludge reactor with phosphate simultaneous precipitation as affected by ferric chloride addition. Chemical Engineering Journal, 165 (2), 607-616. doi: 10.1016/j.cej.2010.10.004.

De Gregorio, C., Caravelli, A. H., \& Zaritzky, N. E. (2011). Application of biological indices and a mathematical model for the detection of metal coagulant overload in a laboratory scale activated sludge reactor with phosphate simultaneous precipitation. Chemical Engineering Journal, 172(1), 52-60. https://doi.org/10.1016/j.cej.2011.05.063.

Jones, P.A., Schuler, A.J. (2012). Role of Changing Biomass Density in Process Disruptions Affecting Biomass Settling at a Full-Scale Domestic Wastewater Treatment Plant. Journal of Environmental Engineering, 138(1), 67-73. doi: 10.1061/(ASCE)EE.1943-7870.0000468.

Koivuranta, E., Keskitalo, J., Stoor, T., Hattuniemi, J., Sarén, M., Niinimäki, J. (2014). A comparison between floc morphology and the effluent clarity at a full-scale activated sludge plant using optical monitoring. Environmental Technology, 35(13), 1605-1610. doi: 10.1080/09593330.2013.875065.

Li, J. (2005). Effects of Fe (III) on floc characteristics of activated sludge. Journal of Chemical Technology \& Biotechnology: International Research in Process, Environmental \& Clean Technology, 80(3), 313-319. Doi: 10.1002/jctb.1169.

Li, H., Wen, Y., Cao, A., Huang, J., Zhou, Q., Somasundaran, P. (2012). The influence of additives (Ca2+, Al3+, and $\mathrm{Fe} 3+$ ) on the interaction energy and loosely bound extracellular polymeric substances (EPS) of activated sludge and their flocculation mechanisms. Bioresource Technology, 114, 188-194. doi: 10.1016/j.biortech.2012.03.043.

Li, B., Stenstrom M.K. (2014). Research advances and challenges in one-dimensional modeling of secondary settling tanks - a critical review, Water Research, 65, 40-63. doi: 10.1016/j.watres.2014.07.007.

Li, Y., Yuan, X., Wang, D., Wang, H., Wu, Z., Jiang, L, Mo, D., Yang, G., Guan R., Zeng, G. (2018). Recyclable zerovalent iron activating peroxymonosulfate synchronously combined with thermal treatment enhances sludge dewaterability by altering physicochemical and biological properties. Bioresource technology, 262, 294-301. doi: 10.1016/j.biortech.2018.04.050.

Liu, X., Xu, Q., Wang, D., Yang, Q., Wu, Y., Yang, J., Gong, J., Ye, J., Li, Y., Wang, Q., Liu, Y., Ni, B., Zeng, G., Li, X. (2018). Revealing the underlying mechanisms of how initial $\mathrm{pH}$ affects waste activated sludge solubilization and dewaterability in freezing and thawing process. ACS Sustainable Chemistry \& Engineering, 6(11), 15822-15831. doi: 10.1021/acssuschemeng.8b04427.

Liu, X., Xu, Q., Wang, D., Wu, Y., Yang, Q., Liu, Y., Wang, Q., Li, X., Zeng, G.,Yang, G. (2019). Unveiling the mechanisms of how cationic polyacrylamide affects short-chain fatty acids accumulation during long-term anaerobic fermentation of waste activated sludge. Water research, 155, 142-151. doi: 10.1016/j.watres.2019.02.036.

Mesquita D.P., Amaral A.L., Ferreira E.C. (2013). Activated sludge characterization through microscopy: review on quantitative image analysis and chemometric techniques. Analytica Chimica Acta, 802, 14-28. doi: 10.1016/j.aca.2013.09.016.

Metcalf and Eddy (2003). Wastewater Engineering: Treatment and Reuse. 4th Edition, McGraw-Hill, New York.

Oikonomidis, I., Burrows, L. J., \& Carliell-Marquet, C. M. (2010). Mode of action of ferric and ferrous iron salts in activated sludge. Journal of Chemical Technology \& Biotechnology, 85(8), 1067-1076. Doi: 10.1002/jctb.2399.

Otal E., Vilches L.F., Luna Y., Poblete R., García-Maya J.M., Fernández-Pereira C. (2013). Ammonium Ion Adsorption and Settleability Improvement Achieved in a Synthetic Zeolite-Amended Activated Sludge. Chinese Journal of Chemical Engineering, 21 (9), 1062-1068. doi: 10.1016/S1004-9541(13)60566-2.

Rebosura M., Salehin S., Pikaar I., Sun X., Keller J., Sharma K., Yuan Z. (2018). A comprehensive laboratory assessment of the effects of sewer-dosed iron salts on wastewater treatment processes. Water Research, 146, 109-117. doi: 10.1016/j.watres.2018.09.021.

Rivas A., Irizar I., Ayesa E. (2007). Model-based optimisation of Wastewater Treatment Plants design. Environmental Modelling \& Software, 23 (4), 435-450. doi: 10.1016/j.envsoft.2007.06.009.

Schuler A.J., Jang H. (2007). Density effects on activated sludge zone settling velocities, Water Research, 41 (8), $1814-$ 1822. doi: 10.1016/j.watres.2007.01.011.

Smith, S., Takács, I., Murthy, S., Daigger, G. T., Szabó, A. (2008). Phosphate complexation model and its implications for chemical phosphorus removal. Water Environment Research, 80(5), 428-438. doi: 10.1002/j.15547531.2008.tb00349.x. 
Suresh, A., Grygolowicz-Pawlak, E., Pathak, S., Poh, L. S., Abdul Majid, M.B., Dominiak, D., Bugge T.V., Gao X., Ng, W. J. (2018). Understanding and optimization of the flocculation process in biological wastewater treatment processes: A review. Chemosphere. 210, 401-416. doi: 10.1016/j.chemosphere.2018.07.021.

Szabó, A., Takács, I., Murthy, S., Daigger, G. T., Licsko, I., Smith, S. (2008). Significance of design and operational variables in chemical phosphorus removal. Water Environment Research, 80(5), 407-416. doi: $10.2175 / 106143008 X 268498$.

Thistleton, J., Berry, T. A., Pearce, P., Parsons, S. A. (2002). Mechanisms of chemical phosphorus removal II: iron (III) salts. Process Safety and Environmental Protection, 80(5), 265-269. doi: 10.1205/095758202762277623.

van Haandel A.C., van der Lubbe J.G.M. (2012). Handbook of Biological Wastewater Treatment - Design and Optimisation of Activated Sludge Systems. $2^{\text {nd }}$ edition. IWA publishing. ISBN: 978-1780407753.

van Loosdrecht, M.C., Nielsen, P.H., Lopez-Vazquez, C.M., Brdjanovic, D. (Eds.). (2016). Experimental Methods in Wastewater Treatment. IWA Publishing. ISBN: 9781780404745.

Vanderhasselt A., Verstraete W. (1999). Short-term effects of additives on sludge sedimentation characteristics. Water Research, 33, 381-390. doi: 10.1016/S0043-1354(98)00204-8.

Wells M., Wareham D. G., Broady P. (2015). The effect of loess addition on the settling ability of activated sludge. Journal of Environmental Science and Health, Part A, 50:7, 728-734, doi: 10.1080/10934529.2015.1011972.

Wiszniowski, J., Surmacz-Górska, J., Robert, D., Weber, J. V. (2007). The effect of landfill leachate composition on organics and nitrogen removal in an activated sludge system with bentonite additive. Journal of environmental management, 85, 59-68. doi: 10.1016/j.jenvman.2006.08.001.

Zhang J., Xia C., Yue Q., Gao B., Yang K., Wu S., Kan Y. (2017). Application of FeCl3 to Adjust Urban SewageDewatered Sludge (UDSS) Containing Cationic Polyacrylamide (CPAM) for Further Dewatering. Water, Air, \& Soil Pollution, 228(6), 196. doi: 10.1007/s11270-017-3377-6. 